Article

\title{
Cutin from Solanum Myriacanthum Dunal and Solanum Aculeatissimum Jacq. as a Potential Raw Material for Biopolymers
}

\author{
Mayra Beatriz Gómez-Patiño ${ }^{1}\left[\right.$, Rosa Estrada-Reyes ${ }^{2}$, María Elena Vargas-Diaz ${ }^{3}$ (i) and \\ Daniel Arrieta-Baez ${ }^{1, *(D)}$ \\ 1 Instituto Politécnico Nacional-CNMN, Unidad Profesional Adolfo López Mateos, Col. Zacatenco, \\ México City CDMX CP 07738, Mexico; bethzem86@gmail.com \\ 2 Laboratorio de Fitofarmacología, Dirección de Investigaciones en Neurociencias, Instituto Nacional de \\ Psiquiatría Ramón de la Fuente Muñiz, Calzada México-Xochimilco 101, San Lorenzo Huipulco, Tlalpan, \\ Ciudad de México 14370, Mexico; restrada@imp.edu.mx \\ 3 Instituto Politécnico Nacional-Departamento de Química Orgánica, Escuela Nacional de Ciencias Biológicas, \\ Prolongación de Carpio y Plan de Ayala S/N, Colonia Santo Tomás D.F. 11340, Mexico; \\ evargasvd@yahoo.com.mx \\ * Correspondence: darrieta@ipn.mx; Tel.: +52-1-55-5729-6000 (ext. 57507)
}

Received: 4 August 2020; Accepted: 26 August 2020; Published: 28 August 2020

\begin{abstract}
Plant cuticles have attracted attention because they can be used to produce hydrophobic films as models for novel biopolymers. Usually, cuticles are obtained from agroresidual waste. To find new renewable natural sources to design green and commercially available bioplastics, fruits of S. aculeatissimum and S. myriacanthum were analyzed. These fruits are not used for human or animal consumption, mainly because the fruit is composed of seeds. Fruit peels were object of enzymatic and chemical methods to get thick cutins in good yields (approximately 77\% from dry weight), and they were studied by solid-state resonance techniques (CPMAS ${ }^{13} \mathrm{C} N M R$ ), attenuated total reflection-Fourier transform infrared spectroscopy (ATR-FTIR), atomic force microscopy (AFM) and direct injection electrospray ionization mass spectrometry (DIESI-MS) analytical methods. The main component of $S$. aculeatissimum cutin is 10,16-dihydroxypalmitic acid (10,16-DHPA, $69.84 \%$ ), while S. myriacanthum cutin besides of 10,16-DHPA (44.02\%); another two C18 monomers: 9,10,18-trihydroxy-octadecanoic acid (24.03\%) and 18-hydroxy-9S,10R-epoxy-octadecanoic acid $(9.36 \%)$ are present. The hydrolyzed cutins were used to produce films demonstrating that both cutins could be a potential raw material for different biopolymers.
\end{abstract}

Keywords: cutin; cuticles; bioplastics; biopolymers; solanum: CPMAS ${ }^{13} \mathrm{C}$ NMR

\section{Introduction}

The cuticle is the outer membrane that covers the aerial parts of plants, such as the stem, leaves, flowers, and fruit. In the evolution of plants, the cuticle plays a critical role against the loss of water from internal tissues [1-3]. In the same way, this biopolymer plays an essential physiological role as it is considered a first barrier that prevents the entry of pathogens and pesticides $[4,5]$. The cuticle consists primarily of cutin (a C16 and C18 long-chain hydroxy acid polyester), cell wall polysaccharides (cellulose, hemicellulose, and pectin), as well as epicuticular fatty acids [6-8]. Cutin, and other important natural biopolymers such as lignin, cellulose, and chitin, has been shown to have important bioplastic properties [9-13]. For this reason, they have been considered as models for plastic materials with biodegradable characteristics that eventually could replace conventional plastics derived from petroleum in specific industrial uses [14]. 
Raw renewable materials have a high impact on the cost of bio-based plastic production and, in this regard, different efforts have been directed to use biomass to get or produce biopolymers. Biopolymers such as starch, cellulose, lignocellulosic materials, and proteins; bio-derived monomers like polylactic acid (PLA), polyglycolic acid (PGA), and biodegradable polymers from petrochemicals (aliphatic polyesters, aromatic co-polyesters and polyvinyl alcohols) have been investigated as sources for bioplastics $[15,16]$.

In this sense, the cutins of some fruits for human consumption, such as tomatoes, citrus have shown good physicochemical characteristics as biopolymers [9,17-20]. However, the ethical problem that could be generated has led researchers to use industrial waste products. In fact, the vegetable food processing industry generates a significant amount of waste worldwide [21]. Thus, from agro-industrial residues, biomaterials have been generated, and some of them have been used in the food packaging industry, and other bioplastic applications [22,23].

In the present work, we have searched for fruits that are not for human consumption, which present the same chemical characteristics of the cuticles used for biopolymers applications in order to be considered promising candidates as a raw material to produce bioplastics. In this sense, the cuticles of the fruits of two species of the Solaneum genus were studied. S. aculeatissimum and S. myriacanthum are shrubs that grow in the wild, covered with thin spines up to $18 \mathrm{~mm}$ long, that produce small fruits of approximately $2-3 \mathrm{~cm}$, which are mainly filled with seeds. S. aculeatissimum is native to Brazil, but it could be found in tropical Africa and Asia. In Mexico, it is distributed in the states of Jalisco, Oaxaca, Chiapas, Veracruz, and Puebla [24]. It is considered a toxic plant due to the alkaloids present in the seeds and leaves [25,26]. Its fruit is green when it is immature and red when it is ripe. S. myriacanthum is native to central and south America, although it is also distributed in Asia, mainly in India. In Mexico, it is distributed in the states of Chiapas, Veracruz, Oaxaca, and Puebla [24]. Anthelmintic properties are attributed to the extracts of the fruit [27]. Its fruit is green when immature and yellow when ripe.

S. aculeatissimum and S. myriacanthum cutins were extracted and analyzed by means of CPMAS ${ }^{13} \mathrm{C}$ NMR, ATR-FTIR, AFM and DIESI-MS, and their components and physicochemical characteristics were determined and compared with other cutin components. From their hydrolyzed components, films were obtained and characterized and, from these results, both Solanum species could be considered as a raw material for biopolymers used in different fields of the plastic industry.

\section{Materials and Methods}

\subsection{Chemicals}

Trifluoroacetic acid (TFA), $\mathrm{KOH}$, and other reagents were purchased from Sigma-Aldrich (St. Louis, MO, USA). The enzymes Aspergillus niger pectinase (EC 3.2.1.15) (specific activity $\geq$ 5 unit/mg protein), A. niger cellulase (EC 3.2.1.4) (specific activity $\geq 0.3$ units/mg protein) and $A$. niger hemicellulose (EC 3.2.1.4) (specific activity 2.3 units/mg protein) were purchased from Sigma Chemicals (St Louis, MO, USA).

\subsection{Isolation of Cutin}

S. aculeatissimum and S. myriacanthum fruits were collected in Cuetzalan, Puebla $\left(20^{\circ} 01^{\prime} 48.7^{\prime \prime} \mathrm{N}\right.$ $97^{\circ} 29^{\prime} 04.3^{\prime \prime} \mathrm{W}$ ) in September 2018. Fruits were washed with tap water, cut, and the seeds were removed to obtain the cuticle. The cutin was obtained using a previously reported protocol [9]. Briefly, the cuticle was treated with A. niger pectinase (EC 3.2.1.15, St Louis, MO, USA) $(10 \mathrm{mg} / \mathrm{mL})$ for 1 week. After this, cell wall polysaccharides were removed with an enzymatic digestion using $A$. niger cellulose (EC 3.2.1.4, St Louis, MO, USA) $(80 \mathrm{mg} / \mathrm{mL})$ for 1 week and A. niger hemicellulose (EC 3.2.1.4, St Louis, MO, USA) ( $80 \mathrm{mg} / \mathrm{mL})$ for 1 week. To complete the extraction, a Soxhlet procedure was done with methylene chloride:methanol (1:1 v/v, $48 \mathrm{~h}$, St Louis, MO, USA) to remove residual compounds of cutin such as monosaccharides and waxes. Five hundred grams of S. aculeatissimum dried peel yielded $386 \mathrm{~g}$ $(77.2 \%)$ of cutin and $500 \mathrm{~g}$ of S. myriacanthum dried peel yielded $394 \mathrm{~g}(78.8 \%)$ of cutin. The resulting 
cutins were analyzed by Cross Polarization Magic-Angle Spinning (CPMAS $\left.{ }^{13} \mathrm{C} N M R\right)$, attenuated total reflection-Fourier transform infrared spectroscopy (ATR-FTIR) and atomic force microscopy (AFM).

\subsection{Treatment of Cutin with Trifluoroacetic Acid (TFA)}

One hundred and fifty milligrams of the obtained cutin from the S. aculeatissimum or S. myriacanthum fruits was added to an aqueous TFA solution $2.0 \mathrm{~mol} \cdot \mathrm{L}^{-1}$ and stirred at $115 \pm 5^{\circ} \mathrm{C}$ for $2 \mathrm{~h}$ in separated experiments. Each reaction was filtered, and the insoluble material was washed using chloroform-methanol (1:1, v/v, St Louis, MO, USA) for $1 \mathrm{~h}$ to obtain the TFA-hydrolyzed cutin (TFA-HC). The TFA-HC was separated by filtration, dried, and analyzed by CPMAS ${ }^{13} \mathrm{C} N M R$. The TFA solution was co-evaporated with methanol and the resulting solids were redissolved in methanol to give a clear brown solution, which was later analyzed by DIESI-MS (Bruker Daltonics, Biellerica, MA, USA) and solution-state NMR (Billerica, MA, USA) [28].

\subsection{Alkaline Hydrolysis of the Cutin with $\mathrm{KOH} / \mathrm{MeOH}$}

Fifty milligrams of S. aculeatissimum or S. myriacanthum cutin was added to $50 \mathrm{~mL}$ of $1.5 \mathrm{~mol} \cdot \mathrm{L}^{-1}$ methanolic $\mathrm{KOH}$ solution, and the mixture was stirred at room temperature for $24 \mathrm{~h}$. After this time, the reaction was filtered, neutralized, and monomers were extracted with $\mathrm{CHCl}_{3}-\mathrm{MeOH}$. The dried extract was weighed, dissolved in $\mathrm{CHCl}_{3}-\mathrm{MeOH}$ and analyzed by DIESI-MS (Bruker Daltonics, Biellerica, MA, USA).

\subsection{Preparation of Cutin Films}

Twenty-five milligrams of hydrolyzed S. aculeatissimum or S. myriacanthum cutin were added to $5 \mathrm{~mL}$ of ultrapure methanol:chloroform $(1: 1, v / v$, St Louis, MO, USA) solution. The solution was sonicated for $30 \mathrm{~s}$ and it was deposited in plastic Petri dishes for making films using the casting method. On the other hand, $5 \mu \mathrm{L}$ of the solution were deposited on a watch glass to study the structures of self-assembled layers. After this, films were kept in a chemical hood to remove residual solvents from the films [29].

\subsection{NMR Spectroscopy}

S. aculeatissimum and S. myriacanthum cutin and TFA-HC were analyzed using standard CPMAS ${ }^{13} \mathrm{C}$ NMR experiments carried out on a Varian Instruments Unityplus 300 widebore spectrometer (Palo Alto, CA, USA) equipped for solid-state NMR. The resonance frequency was $74.443 \mathrm{MHz}$, with a customary acquisition time of $30 \mathrm{~ms}$, a delay time of $2 \mathrm{~s}$ between successive acquisitions and a CP contact time of $1.5 \mathrm{~ms}$. Typically, each $30 \mathrm{mg}$ sample was packed into a $5 \mathrm{~mm}$ rotor and supersonic MAS probe from Doty Scientific (Columbia, SC, USA), then spun at $6.00( \pm 0.1 \mathrm{kHz})$ at room temperature for approximately $10 \mathrm{~h}$. No spinning sidebands were observed upon downfield from the major carbonyl, aromatic, or aliphatic carbon peaks, presumably due to motional averaging and/or excessive broadening of such features.

Soluble products derived from the TFA hydrolysis were examined using ${ }^{1} \mathrm{H}$ NMR. Experiments were conducted on a Bruker Instruments ASCEND 750 spectrometer (Billerica, MA, USA). The resonance frequency was $750.12 \mathrm{MHz}$, with a typical acquisition time of $2.1845 \mathrm{~s}$ and a delay time of $1.0 \mathrm{~s}$ between successive acquisitions. The ${ }^{1} \mathrm{H}$ and ${ }^{13} \mathrm{C}$ chemical shifts are given in units of $\delta$ (ppm), using tetramethylsilane (TMS) as internal standard.

\subsection{ATR-FTIR Spectroscopy}

Attenuated Total Reflectance Fourier transform infrared spectroscopy (ATR-FTIR) spectra were recorded with a BOMEM 157 FTIR spectrometer (Bomem Inc., Quebec, Canada) equipped with a deuterated triglycinesulfate (DTGS) detector. The instrument was under a continuous dry air purge to eliminate atmospheric water vapor. The spectra were recorded in the region of 4000 to $400 \mathrm{~cm}^{-1}$. 


\subsection{Atomic Force Microscopy}

The samples for the Atomic Force Microscopy analysis (AFM) were prepared by fixing to a metallic disk with double-sided tape. The images themselves were taken using a MultiMode AFMV (Bruker, SantaBarbara, CA, USA) in air with an RTESP cantilever, and operating the AFM in tapping mode. The size of each image was $5 \times 5 \mu \mathrm{m}^{2}$. The roughness parameters $R_{\mathrm{q}}$ and $R_{\mathrm{a}}$ were determined using the expressions $R_{\mathrm{q}}=\sqrt{\Sigma \mathrm{Z} 21}=\mathrm{N}$ and $R_{\mathrm{a}}=1=\mathrm{N} \Sigma \mathrm{Nj}=1 \mathrm{jZ} \mathrm{jj}$, where $R_{\mathrm{q}}$ is the root mean square average of the height deviations, $\mathrm{Ra}$ is the arithmetic average of the absolute values of the surface height deviations, $\mathrm{Z}$ is the height value, and $\mathrm{N}$ is the number of data points. These parameters were obtain using the NanoScope Analysis image software.

\subsection{Mass Spectrometry}

Direct Ionization analysis (DIESI-MS) was done on a Bruker MicrOTOF-QII system, using an electrospray ionization (ESI) interface (Bruker Daltonics, Biellerica, MA, USA) operated in the negative ion mode. A solution of $10 \mu \mathrm{L}$ of the sample resuspended in $1 \mathrm{~mL}$ of methanol was filtered with a $0.25 \mu \mathrm{m}$ polytetrafluoroethylene (PTFE) filter and diluted 1:100 with methanol. Diluted samples were directly infused into the ESI source and analyzed in negative mode. Nitrogen was used with a flow rate of $4 \mathrm{~L} / \mathrm{min}(0.4 \mathrm{Bar})$ as a drying and nebulizer gas, with a gas temperature of $180^{\circ} \mathrm{C}$ and a capillary voltage set to $4500 \mathrm{~V}$. The spectrometer was calibrated with an ESI-TOF tuning mix calibrant (Sigma-Aldrich, Toluca, Estado de México, México).

MS/MS analysis was performed using negative electrospray ionization $\left(\mathrm{ESI}^{-}\right)$, and the obtained fragments were analyzed by a Bruker Compass Data Analysis 4.0 (Bruker Daltonics, Technical Note 008, 2004, Bruker Daltonics, Biellerica, MA, USA). An accuracy threshold of 5 ppm was established to confirm the elemental compositions.

\section{Results}

S. aculeatissimum and S. myriacanthum fruits were collected in the Cuetzalan, Puebla (México) region (Figure 1). Usually, the mature fruit is a globose berry $2-3 \mathrm{~cm}$ in diameter, and it is composed of the peel $(\approx 0.2 \mathrm{~mm}$ thick) that represent a $25-30 \%$ percent of the fruit, $10 \%$ of a polysaccharides layer, and $50-60 \%$ of seeds. Once the peels were washed and dried, cutins were obtained by previously published methods. Cutin obtained from the dry peels were in very high yield $(\approx 77 \%)$ in relation to other fruit cutins, such as tomato or citrus fruits $(\approx 0.5 \%)[9,30]$. Most of the compounds hydrolyzed with the enzymatic treatment were identified as monosaccharides (Glu and Fru, data not shown), and cutins were characterized by solid-state resonance techniques (CPMAS ${ }^{13} \mathrm{C}$ NMR), ATR-FTIR, and AFM.

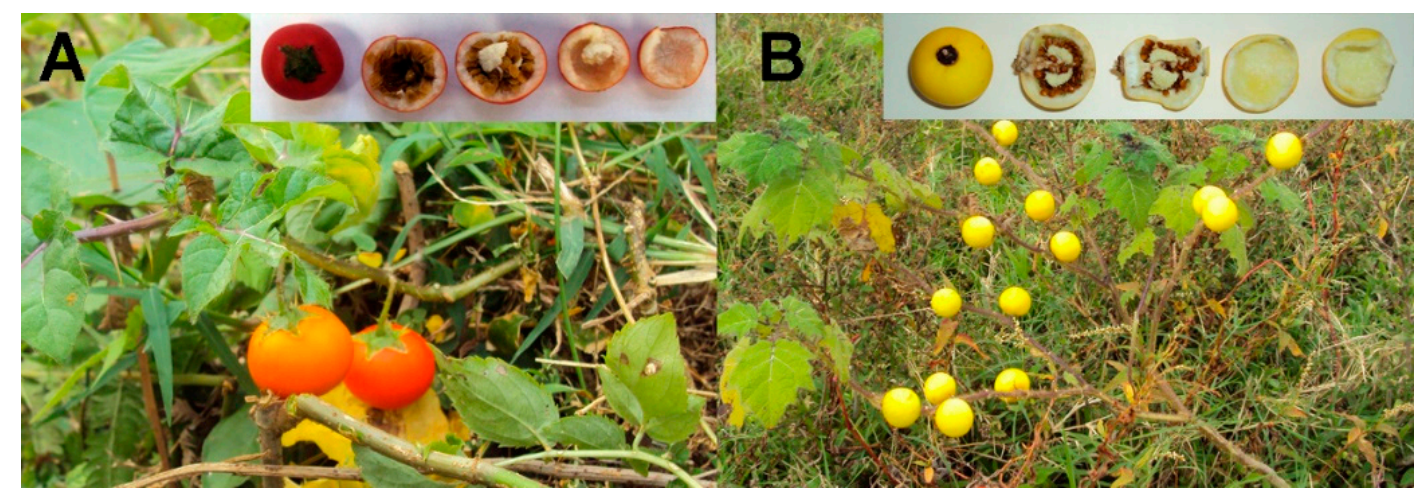

Figure 1. Photographs of the plants and fruits of (A) S. aculeatissimum Jacq, and (B) S. myriacanthum Dunal. 


\subsection{CPMAS ${ }^{13} \mathrm{C}$ NMR Analysis}

Cutins obtained from S. aculeatissimum and S. myriacanthum were analyzed by CPMAS ${ }^{13} \mathrm{C}$ NMR, and their spectra are shown in Figure 2. According to our previous studies in fruit cuticles, typical resonances of aliphatic-aromatic polyesters are exhibited: bulk methylenes (20-35 ppm), oxygenated aliphatic carbons (55-85 ppm), aromatics and olefins (105-155 ppm), and carbonyl groups (172 ppm) signals.

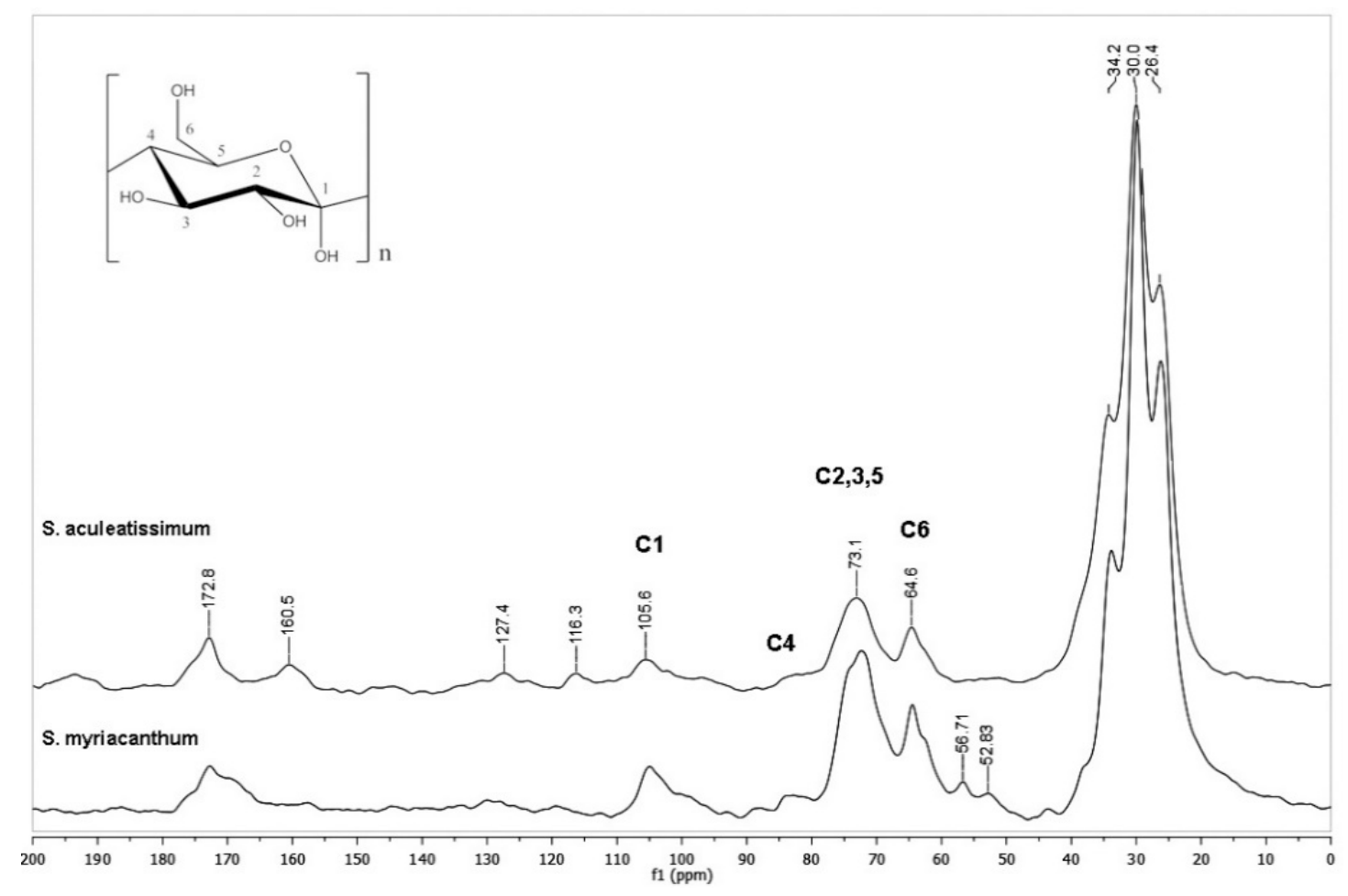

Figure 2. CPMAS ${ }^{13} \mathrm{C}$ NMR spectra of cutins from S. aculeatissimum and S. myriacanthum.

Some of these signals belong to the carbohydrate moieties (C6 at $60 \mathrm{ppm}, \mathrm{C} 2,3,5$ at 70-75 ppm, $\mathrm{C} 4$ at 83 ppm, and C1 at 101-105 ppm), some of these peaks could overlap with oxygenated aliphatic signals. However, every cutin showed unique NMR characteristics: more aromatic peaks are evident in S. aculeatissimum (Figure 2, upper spectrum), while in S. myriacanthum (Figure 2, lower spectrum) peaks at 52 and 56 ppm are present.

To garner more information about these materials, cutins from both fruits were the object of a TFA hydrolysis. It has been demonstrated that TFA hydrolysis could be used to remove non-cellulosic polysaccharides with the advantage that TFA is easy to remove by evaporation rather than a loss-prone neutralization step [28].

S. aculeatissimum cutin was found to be resistant to TFA hydrolysis. There was a minimal weight loss, and as seen in Figure 3, and most of the peaks remain as in the spectra without TFA treatment. However, $S$. myriacanthum shows $\approx 8 \%$ of weight loss, and this can be attributed to the disappearance of compounds with peaks at $50 \mathrm{ppm}$. The soluble part obtained from the TFA hydrolysis was studied, and it was found that these peaks belong to an epoxidated C18 long-chain aliphatic acid (see Supplementary Material). 


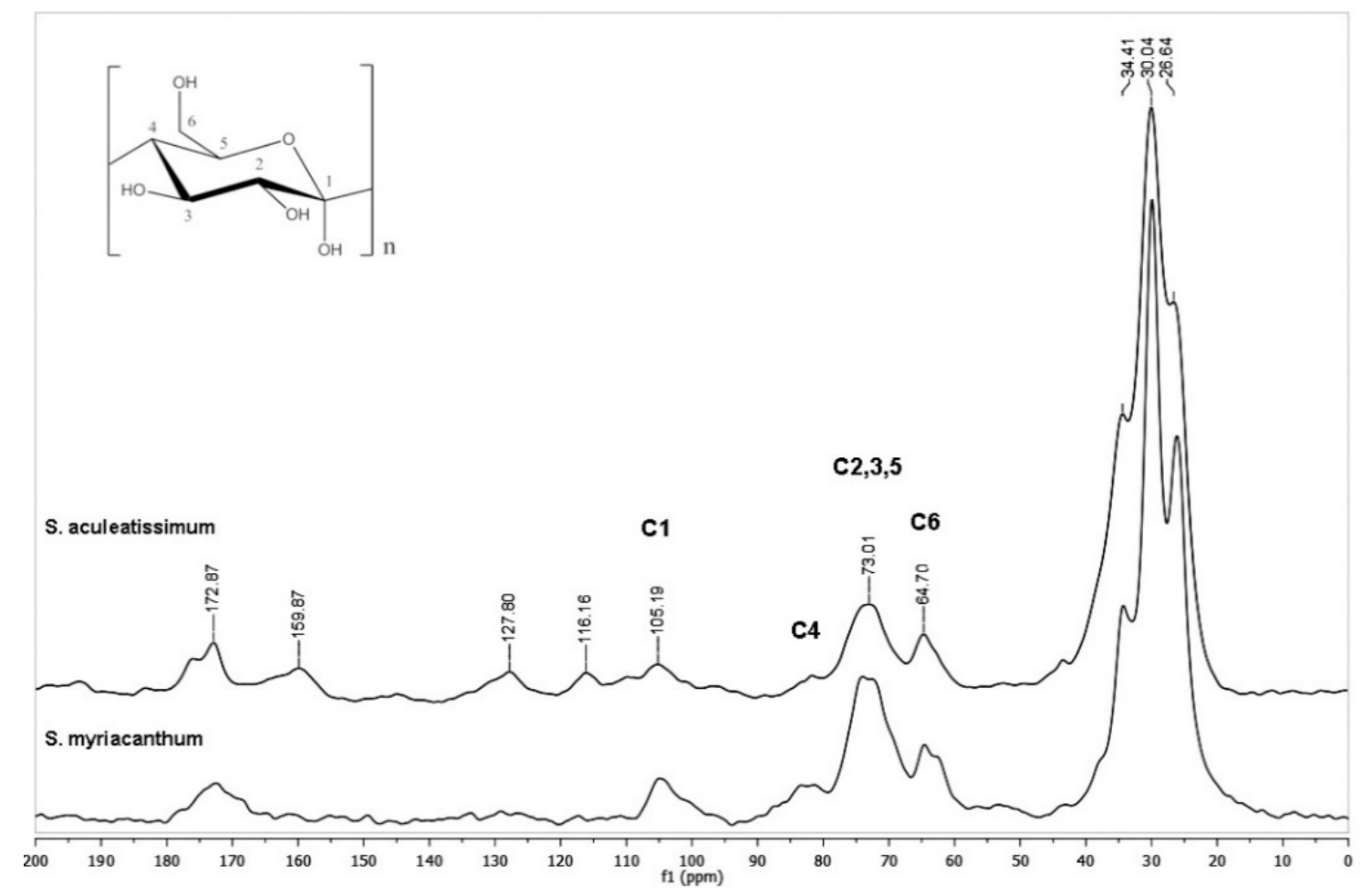

Figure 3. CPMAS ${ }^{13} \mathrm{C}$ NMR spectra of cutins from S. aculeatissimum and S. myriacanthum after trifluoracetic acid (TFA) hydrolysis (TFA-HC).

\subsection{Infrared Spectroscopy Analysis of the S. Aculeatissimum and S. Myriacanthum Cutins}

Isolated cutins have been characterized in situ at their functional chemical groups as well as their interactions at the cuticular levels with exogenous chemicals [8,31]. The ATR FT-IR analysis of S. aculeatissimum and S. myriacanthum cutins (Figure 4) were characterized as follows: hydroxyl groups of the polysaccharide domain and residual carboxylic acids showed its absorption maxima as broadband at $3860 \mathrm{~cm}^{-1}$, characteristic intense bands corresponding to the asymmetrical and symmetrical stretching vibrations of the methylene $\mathrm{CH}_{2}$ region at 2905 and $2850 \mathrm{~cm}^{-1}$, with the bending vibrations at 1462 and $1350 \mathrm{~cm}^{-1}$, which came from the aliphatic components present in the cutin. Another group of signals associated with the cutin matrix is that from 1600 to $1750 \mathrm{~cm}^{-1}$ attributed to the carbonyl $\mathrm{C}=\mathrm{O}$ stretching band in ester groups, and their asymmetric stretching vibrations of $\mathrm{C}-\mathrm{CO}-\mathrm{O}$ at $1100 \mathrm{~cm}^{-1}$. These assignations agree with those reported and used in the study of non-isolated plant cutins [8].

Figure 4 shows that IR spectra for both cutins are very similar, and the most intense bands correspond to the main domains of this polyester: aliphatic and polysaccharides groups. However, two groups of signals are making the difference between them. For S. aculeatissimum cutin, a group of bands at 1500 to $1650 \mathrm{~cm}^{-1}$ related to aromatic and $\mathrm{C}=\mathrm{C}$ functional groups are less intense in $S$. myriacanthum cutin, due to the low presence of aromatics. On the other hand, the group of signals at $1100 \mathrm{~cm}^{-1}$ is broader and more intense in S. myriacanthum, possibly because of a poliesterification with at least two different long-chain acids. These observations agreed with the CPMAS ${ }^{13} \mathrm{C}$ NMR analysis. 


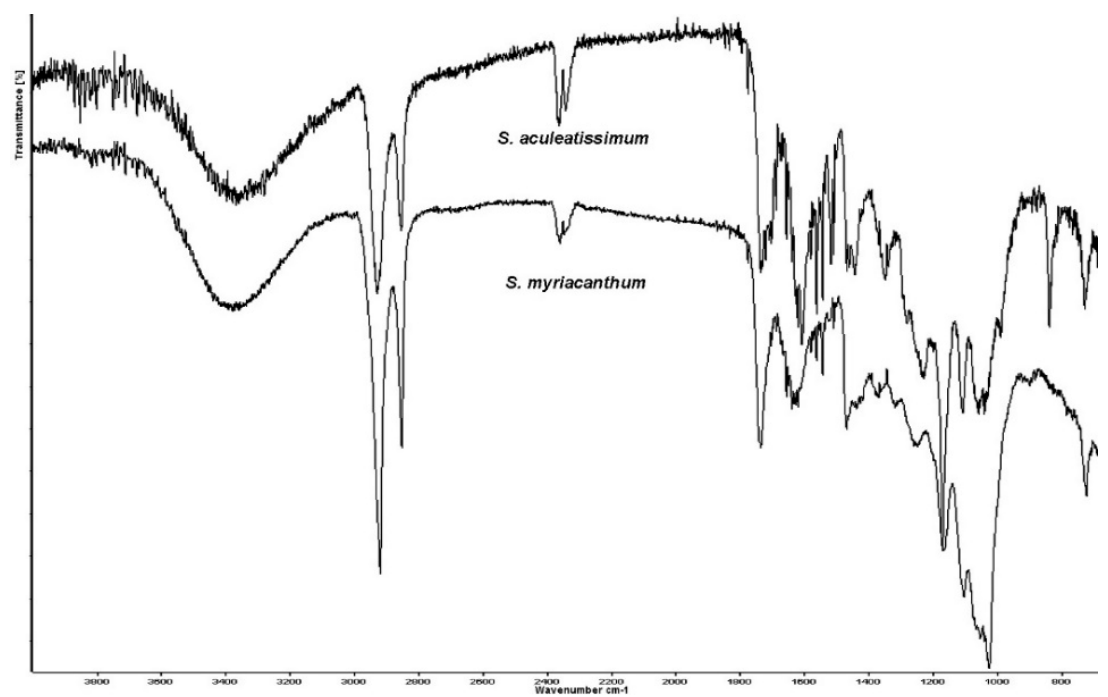

Figure 4. Attenuated Total Reflectance Fourier transform infrared spectroscopy (ATR-FTIR) spectra of S. aculeatissimum and S. myriacanthum.

\subsection{Atomic Force Microscopy Analysis}

The cuticles obtained from the fruits of S. aculeatissimum and S. myriacanthum were analyzed through AFM. Figure 5 shows that these cutins are thicker than other fruit cutins, such as tomatoes, lemon, orange. The AFM amplitude error images showed that cutin surfaces are composed mainly of fibers that give the characteristic roughness (Figure 5C,D). The fibers are more homogeneous in the S. aculeatissimum cutin with an average thickness of $34 \mathrm{~nm}$, while in the S. myriacanthum cutin they are irregularly present, with fibers ranged from 125 to $23 \mathrm{~nm}$ that were observed. The roughness study showed that $S$. aculeatissimum has a $R_{\mathrm{q}}$ of $1.8 \mathrm{~nm}$ and a $R_{\mathrm{a}}$ of $1.3 \mathrm{~nm}$, while the cutin of $S$. myriacanthum showed a lower roughness with a $R_{\mathrm{q}}$ of $3.4 \mathrm{~nm}$ and a $R_{\mathrm{a}}$ of $2.6 \mathrm{~nm}$.

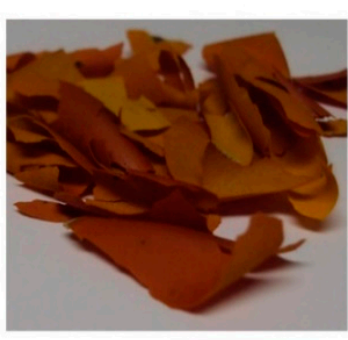

A

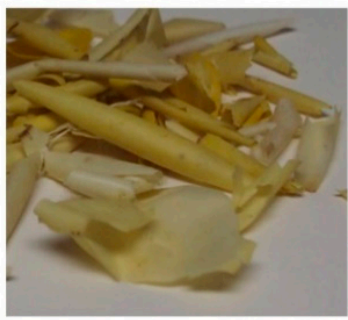

D

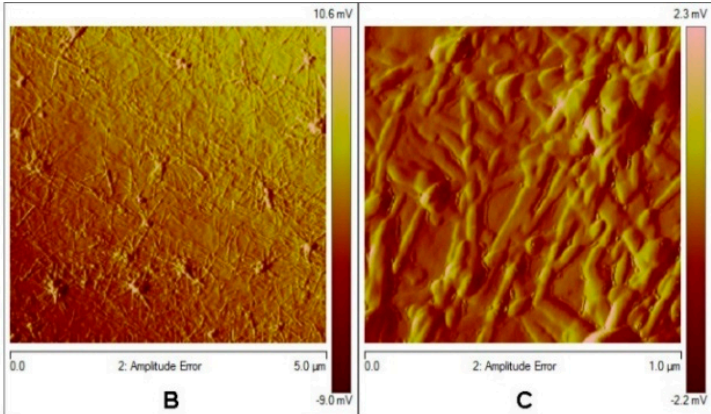

B
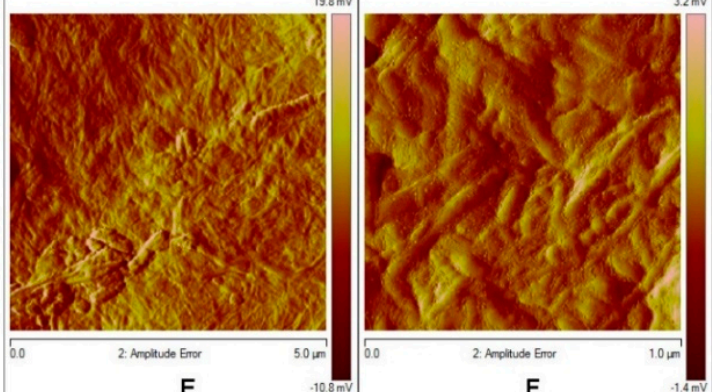

$\mathbf{F}$

Figure 5. Atomic force microscopy tapping mode topographical images from (A) S. aculeatissimum (B,C): 5.0 and $1.0 \mu \mathrm{m}$, respectively) and (D) S. myriacanthum (E,F): 5.0 and $1.0 \mu \mathrm{m}$, respectively). 


\subsection{Alkaline Hydrolysis ( $\mathrm{KOH} / \mathrm{MeOH})$}

To study the main aliphatic components present in the S. aculeatissimum and S. myriacanthum cutins, a complementary analysis was done with alkaline hydrolysis. In both cases, around $\approx 93 \%$ of the cuticular material was hydrolyzed. Soluble products from the alkaline hydrolysis were analyzed by means of direct-injection electrospray ionization mass spectrometry in negative mode (DIESI-MS, see Supplementary Material) and the compounds identified by the $m s / m s$ analysis, are reported in Table 1.

Table 1. Identification of the Main Compounds in the Soluble Fraction of the Alkaline Hydrolysis.

\begin{tabular}{|c|c|c|c|c|c|c|}
\hline \multirow{2}{*}{ Name } & \multirow{2}{*}[\mathbf{M}-\mathbf{H}]{$^{-}$obs } & \multirow{2}{*}[\mathbf{M}-\mathbf{H}]{$^{-}$exact } & \multirow{2}{*}{ Formula } & \multirow{2}{*}{ Error } & \multicolumn{2}{|c|}{$\%$ RA } \\
\hline & & & & & SA & SM \\
\hline Coumaric acid & 163.0386 & 163.0389 & $\mathrm{C}_{9} \mathrm{H}_{8} \mathrm{O}_{3}$ & 2.1 & 0.18 & - \\
\hline Capric acid & 171.1352 & 171.1379 & $\mathrm{C}_{10} \mathrm{H}_{20} \mathrm{O}_{2}$ & 3.5 & 0.36 & 0.25 \\
\hline Coniferaldehyde & 177.0557 & 177.0546 & $\mathrm{C}_{10} \mathrm{H}_{10} \mathrm{O}_{3}$ & 3.6 & 0.54 & - \\
\hline n-Nonanedioic acid & 187.1001 & 187.0964 & $\mathrm{C}_{9} \mathrm{H}_{16} \mathrm{O}_{4}$ & 4.1 & 0.18 & 0.25 \\
\hline Ferulic acid & 193.0473 & 193.0495 & $\mathrm{C}_{10} \mathrm{H}_{10} \mathrm{O}_{4}$ & 2.5 & 0.18 & - \\
\hline Lauric acid & 199.1689 & 199.1692 & $\mathrm{C}_{12} \mathrm{H}_{24} \mathrm{O}_{2}$ & 2.5 & 0.18 & 0.25 \\
\hline Myristic acid & 227.2003 & 227.2005 & $\mathrm{C}_{14} \mathrm{H}_{28} \mathrm{O}_{2}$ & 1.9 & 0.72 & 1.02 \\
\hline n-Pentadecanoic acid & 241.2144 & 241.2162 & $\mathrm{C}_{15} \mathrm{H}_{30} \mathrm{O}_{2}$ & 3.9 & 0.72 & 1.02 \\
\hline Palmitic acid & 255.2322 & 255.2318 & $\mathrm{C}_{16} \mathrm{H}_{32} \mathrm{O}_{2}$ & 2.0 & 2.88 & 3.29 \\
\hline Hexyl 2-(4-hydroxy-3-methoxy-phenyl) acetate & 265.1481 & 265.1434 & $\mathrm{C}_{15} \mathrm{H}_{22} \mathrm{O}_{4}$ & 4.2 & - & 1.77 \\
\hline 16-hydroxypalmitic acid & 271.2257 & 271.2267 & $\mathrm{C}_{16} \mathrm{H}_{32} \mathrm{O}_{3}$ & 2.6 & 6.12 & 1.52 \\
\hline Linoleic acid & 279.2330 & 279.2318 & $\mathrm{C}_{18} \mathrm{H}_{32} \mathrm{O}_{2}$ & 3.1 & & 2.02 \\
\hline 10,16-DHPA & 287.2209 & 287.2216 & $\mathrm{C}_{16} \mathrm{H}_{32} \mathrm{O}_{4}$ & 2.6 & 69.84 & 44.02 \\
\hline Heptadecanedioic acid & 299.2228 & 299.2216 & $\mathrm{C}_{17} \mathrm{H}_{32} \mathrm{O}_{4}$ & 3.4 & 2.88 & 1.26 \\
\hline 8-hydroxyhexadecane dioic acid & 301.2017 & 301.2009 & $\mathrm{C}_{16} \mathrm{H}_{30} \mathrm{O}_{5}$ & 4.2 & 5.76 & 1.52 \\
\hline 18-hydroxy-9S,10R-epoxy-octadecanoic acid & 313.2387 & 313.2373 & $\mathrm{C}_{18} \mathrm{H}_{34} \mathrm{O}_{4}$ & 3.9 & - & 9.36 \\
\hline 9,10,18-trihydroxy-octadecanoic acid & 331.2487 & 331.2479 & $\mathrm{C}_{18} \mathrm{H}_{36} \mathrm{O}_{5}$ & 2.4 & 2.88 & 24.03 \\
\hline 2,3-Divanillyl-1,4-butanediol & 361.1563 & 361.1645 & $\mathrm{C}_{20} \mathrm{H}_{26} \mathrm{O}_{6}$ & 4.5 & 2.16 & 4.05 \\
\hline
\end{tabular}

$[\mathrm{M}-\mathrm{H}]^{-}$exact: Molecular Weight exact, $[\mathrm{M}-\mathrm{H}]^{-}$obs: Molecular Weight observed, \% RA: \% Relative Area. Error [ppm]: Absolute value of the deviation between measured mass and theoretical mass of the selected peak in [ppm].

Even when most of the compounds are present in both cutins, some differences can be observed. The main constituent identified in S. aculeatissimum cutin was 10,16-dihydroxyhexadecanoic acid (10,16-DHPA), an important monomer present in different cutins such as tomato, citrus cuticles and green pepper [32], in a $69.84 \%$ of the relative abundance. Aromatic and some derivatives compounds were detected in agreement with the CPMAS ${ }^{13} \mathrm{C}$ NMR data. 10,16-DHPA was found in S. myriacanthum cutin. However, two other significant monomers are present: 9,10,18-trihydroxy-octadecanoic acid and 18-hydroxy-9S,10R-epoxy-octadecanoic acid in 24.03 and $9.36 \%$, respectively. According to the TFA-hydrolysis analysis, the epoxilated long-chain aliphatic acid was hydrolyzed and obtained almost pure, according to the NMR analysis (see Supplementary Material). This observation could suggest that it is present in a different domain from the other components. The predominance of C16 long-chain acids in cutins is very common and corroborates previous cutin reports. However, it is important to highlight that most of the $25 \%$ of the main monomers in S. myriacanthum cutin are $\mathrm{C} 18$ acids. The presence of these $\mathrm{C} 16$ and $\mathrm{C} 18$ monomers could be the reason for the broadband esterification detected at $100 \mathrm{~cm}^{-1}$ in the ATR-FTIR spectrum. Aromatic compounds are not present as in S. aculeatissimum cutin, which agrees with the NMR analysis.

\subsection{Analysis of the Films Prepared from Hydrolyzed Cutins}

To demonstrate that S. aculeatissimum and S. myriacanthum cutins could be a good material for biopolymer, films were prepared by simple blending in solvents. Representative photographs of the films prepared from the hydrolyzed cutins are shown in Figure 6. Both samples have a waxy consistency, but their surface was quite homogeneous. Films were characterized through ATR-FTIR and AFM. 


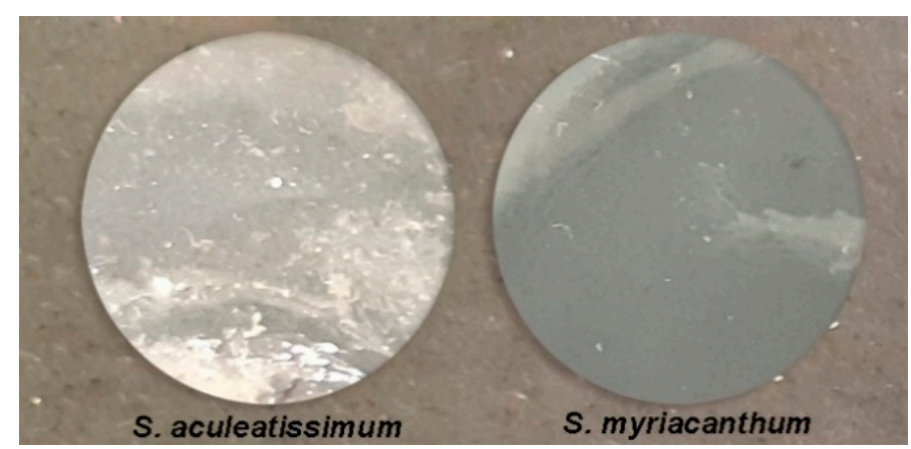

Figure 6. Photographs of the films prepared from hydrolyzed cutins.

\subsection{ATR-FTIR Analysis of the Films}

Analysis using Fourier transform infrared (FTIR) spectroscopy indicated that films from hydrolyzed cutins keep the spectral features of the original cutins. However, most of the signals demonstrate that bands associated with ester groups disappeared, especially the absorption at $1630 \mathrm{~cm}^{-1}$ that belongs to the stretching of $\mathrm{C}=\mathrm{O}$ of ester groups. However, the presence of the band at $1127 \mathrm{~cm}^{-1}$, ascribed to the asymmetric stretching vibrations of $\mathrm{C}-\mathrm{CO}-\mathrm{O}$, demonstrates that part of this polyester network remains, or monomers were partially polymerized (Figure 7).

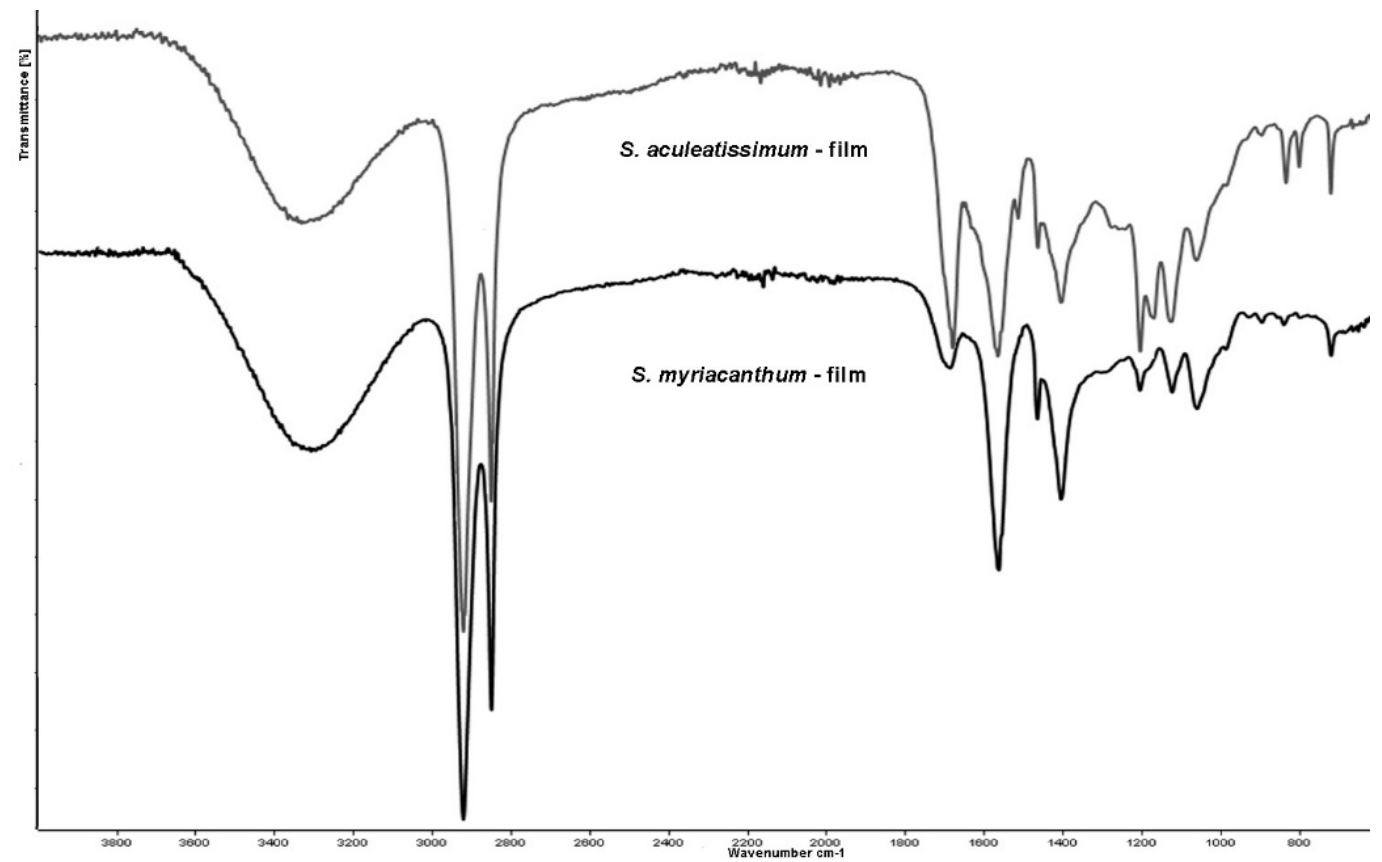

Figure 7. ATR-FTIR spectra of the films from hydrolyzed cutins of S. aculeatissimum and S. myriacanthum.

\subsection{AFM Analysis of the Films}

Atomic Force Microscopy (AFM) analysis shows a different topography from that observed in the original cutins. There is no occurrence of fibers that could be attributed to the cellulose or pectin presence [33]. According to DIESI-MS analysis, there is not a presence of sugars or some oligoor polysaccharides in the soluble hydrolyzed cutins. The roughness study showed that film from S. aculeatissimum cutin has a value of a $R_{\mathrm{q}} 0.527 \mathrm{~nm}$ and a $R_{\mathrm{a}} 0.406 \mathrm{~nm}$, while that obtained from S. myriacanthum cutin showed values of $R_{\mathrm{q}} 0.973 \mathrm{~nm}$ and Ra $0.584 \mathrm{~nm}$ (Figure 8). 

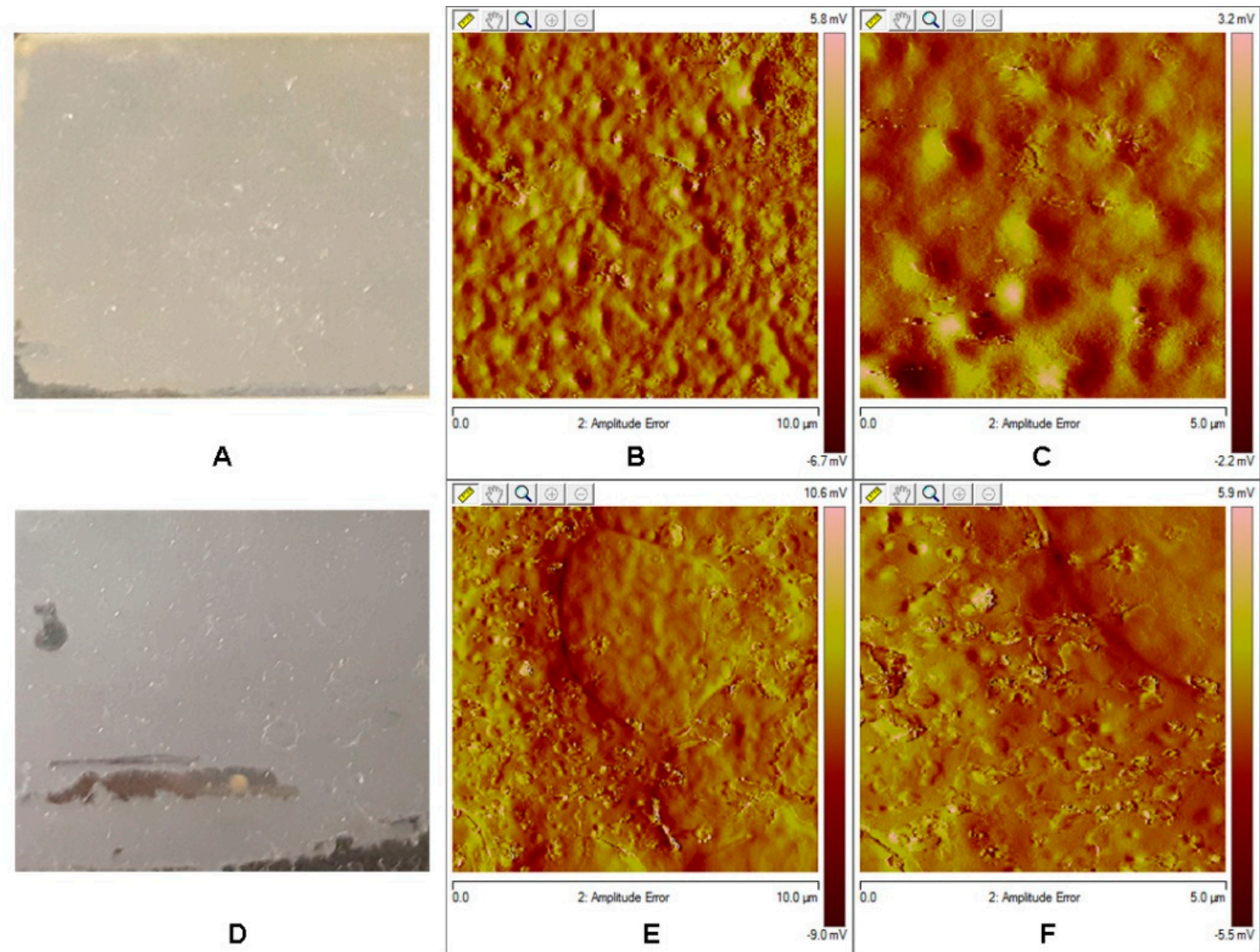

Figure 8. Atomic force microscopy tapping mode topographical images from (A) S. aculeatissimum (B,C): 5.0 and $1.0 \mu \mathrm{m}$, respectively) and (D) S. myriacanthum (E,F): 5.0 and $1.0 \mu \mathrm{m}$, respectively).

The homogeneity could be attributed to a good organization and a high degree of order of the monomers, oligomers or polymers present in the hydrolyzed cutin. This characteristic is highly important to get films with small porous or cavities distributed along the surface.

\section{Conclusions}

In this work, we have demonstrated that S. aculeatissimum and S. myriacanthum cuticles have a good percentage of cutin-around $70 \%$, from the dry weight, more than other studied fruits such as tomato or citrus fruits $(\approx 0.5 \%)$. These cutins have the same monomers composition reported in other fruits cuticles such as tomato, citric fruits, or pepper, were the main component was 10,16-DHPA. Films obtained from the hydrolyzed cutins showed a good homogeneity. Furthermore, the fact that these fruits are not for human or animal consumption makes it feasible for them to be considered as a potential raw material to produce sustainable composite materials as an alternative to traditional plastics.

Supplementary Materials: The Supplementary Materials are available online at http://www.mdpi.com/2073-4360/ 12/9/1945/s1.

Author Contributions: M.B.G.-P. and D.A.-B. conceived and designed the main ideas of this paper, carried out the NMR and DIESI-MS experiments, analyzed the experimental results, and wrote the paper. R.E.-R., and M.E.V.-D. carried out the cuticle and compounds extraction experiments and help to discuss the results. The authors read and approved the final manuscript. Investigation, D.A.B, R.E.-R., M.E.V.-D. and M.B.G.-P.; Project administration, D.A.B and M.B.G.-P.; Supervision, D.A.B and M.B.G.-P. All authors have read and agreed to the published version of the manuscript.

Funding: This research was funded by Consejo Nacional de Ciencia y Tecnologia (CONACyT) for funding Project No. 253570 and SIP-IPN grants No. 20201066 and 20201968. 
Conflicts of Interest: The authors declare no conflict of interest. The funders had no role in the design of the study; in the collection, analyses, or interpretation of data; in the writing of the manuscript, or in the decision to publish the results.

\section{References}

1. Bargel, H.; Koch, K.; Cerman, Z.; Neinhuis, C. Structure-Function Relationships of the Plant Cuticle and Cuticular Waxes-A Smart Material? Funct. Plant Biol. 2006, 33, 893-910. [CrossRef] [PubMed]

2. Dominguez, E.; Heredia-Guerrero, J.A.; Heredia, A. The Biophysical Design of Plant Cuticles: An Overview. N. Phytol. 2011, 189, 938-949. [CrossRef]

3. Fich, E.A.; Segerson, N.A.; Rose, J.K. The Plant Polyester Cutin: Biosynthesis, Structure, and Biological Roles. Annu. Rev. Plant Biol. 2016, 67, 207-233. [CrossRef] [PubMed]

4. Kolattukudy, P.E. Polyesters in Higher Plants. Adv. Biochem. Eng. Biotechnol. 2001, 71, 1-49. [PubMed]

5. Burghardt, M.; Riederer, M. Cuticular transpiration. In Biology of the Plant Cuticle; Riederer, M., Müller, C., Eds.; Blackwell Publishing: Oxford, UK, 2006; pp. 292-311.

6. Walton, T.J.; Kolattukudy, P.E. Determination of the structures of cutin monomers by a novel depolymerization procedure and combined gas chromatography and mass spectrometry. Biochemistry 1972, 11, 1885-1897. [CrossRef]

7. Waltson, T. Waxes, cutin and suberin. In Lipids, Membranes and Aspects of Photobiology; Harwood, E.J., Boyer, J., Eds.; Academic Press: London, UK, 1990; pp. 105-158.

8. Heredia-Guerrero, J.A.; Benitez, J.J.; Dominguez, E.; Bayer, I.S.; Cingolani, R.; Athanassiou, A.; Heredia, A. Infrared and Raman spectroscopic features of plant cuticles: A review. Front. Plant Sci. 2014, 5, 305. [CrossRef]

9. Arrieta-Baez, D.; Cruz-Carrillo, M.; Gómez-Patiño, M.B.; Zepeda-Vallejo, L.G. Derivatives of 10,16-dihydroxyhexadecanoicacid isolated from tomato (Solanum lycopersicum) as potential material for aliphatic polyesters. Molecules 2011, 16, 4923-4936. [CrossRef]

10. Tedeschi, G.; Guzman-Puyol, S.; Ceseracciu, L.; Paul, U.C.; Picone, P.; Di, C.M.; Athanassiou, A.; Heredia-Guerrero, J.A. Multifunctional Bioplastics Inspired by Wood Composition: Effect of Hydrolyzed Lignin Addition to Xylan-Cellulose Matrices. Biomacromolecules 2020, 21, 910-920. [CrossRef]

11. Yang, J.; Ching, Y.C.; Chuah, C.H. Applications of Lignocellulosic Fibers and Lignin in Bioplastics: A Review. Polymers 2019, 11, 751. [CrossRef]

12. Reichert, C.L.; Bugnicourt, E.; Coltelli, M.B.; Cinelli, P.; Lazzeri, A.; Canesi, I.; Braca, F.; Martinez, B.M.; Alonso, R.; Agostinis, L.; et al. Bio-Based Packaging: Materials, Modifications, Industrial Applications and Sustainability. Polymers 2020, 12, 1558. [CrossRef]

13. Liu, D.; Yan, X.; Si, M.; Deng, X.; Min, X.; Shi, Y.; Chai, L. Bioconversion of Lignin into Bioplastics by Pandoraea Sp. B-6: Molecular Mechanism. Environ. Sci. Pollut. Res. Int. 2019, 26, 2761-2770. [CrossRef] [PubMed]

14. Kershaw, P. Exploring the Potential for Adopting Alternative Materials to Reduce Marine Plastic Litter; United Nations Environment Programme: Nairobi, Kenya, 2018; pp. 1-124.

15. Coles, R.; Kay, M.; Song, J. Bioplastics. In Food and Beverage Packaging Technology, 2nd ed.; Coles, R., Kirwan, C.M., Eds.; Blackwell Publishing Ltd.: Hoboken, NJ, USA, 2011; pp. 295-319.

16. Mostafa, N.A.; Farag, A.A.; Abo-dief, H.L.; Tayeb, A.M. Production of biodegradable plastic from agricultural wastes. Arab. J. Chem. 2018, 11, 546-553. [CrossRef]

17. Giosafatto, C.V.; Di, P.P.; Gunning, P.; Mackie, A.; Porta, R.; Mariniello, L. Characterization of Citrus Pectin Edible Films Containing Transglutaminase-Modified Phaseolin. Carbohydr. Polym. 2014, 106, 200-208. [CrossRef] [PubMed]

18. Baron, R.D.; Perez, L.L.; Salcedo, J.M.; Cordoba, L.P.; Sobral, P.J. Production and Characterization of Films Based on Blends of Chitosan from Blue Crab (Callinectes Sapidus) Waste and Pectin from Orange (Citrus Sinensis Osbeck) Peel. Int. J. Biol. Macromol. 2017, 98, 676-683. [CrossRef] [PubMed]

19. Naz, S.; Ahmad, N.; Akhtar, J.; Ahmad, N.M.; Ali, A.; Zia, M. Management of Citrus Waste by Switching in the Production of Nanocellulose. IET Nanobiotechnol. 2016, 10, 395-399. [CrossRef] [PubMed] 
20. Arrieta-Baez, D.; Hernandez Ortiz, J.V.; Teran, J.C.; Torres, E.; Gomez-Patino, M.B. Aliphatic Diacidic Long-Chain C16 Polyesters From 10,16-Dihydroxyhexadecanoic Acid Obtained from Tomato Residual Wastes. Molecules 2019, 24, 1524. [CrossRef]

21. Gómez-Patiño, M.B.; López-Simeón, R.; Espinosa-Domínguez, S.; Hernández-Guerrero, M.; Arrieta-Baez, D.; Beltrán-Conde, H.; Campos-Terán, J.; Reyes-Duarte, D. Aprovechamiento de residuos agroindustriales: Composición, modificación enzimática y evaluación de sus potenciales aplicaciones in Obtención Enzimática de Ingredientes Funcionales, Compuestos Bioactivos y Nutraceúticos a Partir de Recursos Naturales Iberoamericanos. In Biblioteca de las Ciencias, 40th ed.; Fabián, G.C.S., Gasca, F.J.P., Eds.; Consejo Superior de Investigaciones Científicas: Madrid, Spain, 2012.

22. Benitez, J.J.; Osbild, S.; Guzman-Puyol, S.; Heredia, A.; Heredia-Guerrero, J.A. Bio-Based Coatings for Food Metal Packaging Inspired in Biopolyester Plant Cutin. Polymers 2020, 12, 942. [CrossRef]

23. Heredia-Guerrero, J.A.; Heredia, A.; Dominguez, E.; Cingolani, R.; Bayer, I.S.; Athanassiou, A.; Benitez, J.J. Cutin From Agro-Waste As a Raw Material for the Production of Bioplastics. J. Exp. Bot. 2017, 68, 5401-5410. [CrossRef]

24. Cuevas-Reyes, L. Taxonomía de la Familia Solanaceae en el Municipio de Coacoatzintla. Bachelor's Thesis, Facultad de Biología, Universidad Veracruzana, Veracruz, Mexico, 2018.

25. Kohara, A.; Nakajima, C.; Hashimoto, K.; Ikenaga, T.; Tanaka, H.; Shoyama, Y.; Yoshida, S.; Muranaka, T. A Novel Glucosyltransferase Involved in Steroid Saponin Biosynthesis in Solanum Aculeatissimum. Plant Mol. Biol. 2005, 57, 225-239. [CrossRef]

26. Ikenaga, T.; Kikuta, S.; Itimura, K.; Nakashima, K.; Matsubara, T. Growth and Production of Steroid Saponin in Solanum Aculeatissimum during One Vegetation Period. Planta Med. 1988, 54, 140-142. [CrossRef]

27. Yadav, A.K.; Tangpu, V. Anthelmintic Activity of Ripe Fruit Extract of Solanum Myriacanthum Dunal (Solanaceae) Against Experimentally Induced Hymenolepis Diminuta (Cestoda) Infections in Rats. Parasitol. Res. 2012, 110, 1047-1053. [CrossRef] [PubMed]

28. Arrieta-Baez, D.; Stark, R.E. Using Trifluoroacetic Acid to Augment Studies of Potato Suberin Molecular Structure. J. Agric. Food Chem. 2006, 54, 9636-9641. [CrossRef] [PubMed]

29. Gomez-Patiño, M.B.; Cassani, J.; Jaramillo-Flores, M.E.; Zepeda-Vallejo, L.G.; Sandoval, G.; Jimenez-Estrada, M.; Arrieta-Baez, D. Oligomerization of 10,16-Dihydroxyhexadecanoic Acid and Methyl 10,16-Dihydroxyhexadecanoate Catalyzed by Lipases. Molecules 2013, 18, 9317-9333. [CrossRef] [PubMed]

30. Hernandez, V.B.L.; Arrieta-Baez, D.; Cortez, S.P.I.; Méndez-Méndez, J.V.; Berdeja, M.B.M.; Gómez-Patiño, M.B. Comparative studies of cutins from lime (Citrus aurantifolia) and grapefruit (Citrus paradisi) after TFA hydrolysis. Phytochemistry 2017, 144, 78-86. [CrossRef]

31. Luque, P.; Ramírez, F.J.; Heredia, A.; Bukovac, M.J. Fouriertrans-form IR studies on the interaction of selected chemicals with isolates cuticles. In Air Pollutants and the Leaf Cuticle, NATO ASI Series, G36; Percy, K.E., Cape, J.N., Jagels, R., Simpson, C.J., Eds.; Springer: Berlin, Germany, 1994; pp. 217-223.

32. Gerard, H.C.; Osman, S.F.; Fett, W.F.; Moreau, R.A. Separation, identification and quantification of monomers from cutin polymers by high performance liquid chromatography and evaporative light scattering detection. Phytochem. Anal. 1992, 3, 139-144. [CrossRef]

33. Posé, S.; Paniagua, C.; Matas, A.J.; Gunning, A.P.; Morris, V.M.; Quesada, M.A.; Mercado, J.A. A nanostructural view of the cell wall disassembly process during fruit ripening and postharvest storage by atomic force microscopy. Trends Food Sci. Technol. 2019, 87, 47-58. [CrossRef]

(C) 2020 by the authors. Licensee MDPI, Basel, Switzerland. This article is an open access article distributed under the terms and conditions of the Creative Commons Attribution (CC BY) license (http://creativecommons.org/licenses/by/4.0/). 